\title{
An exploratory study of the perspectives of clinical preceptors about difficult student situations during clinical teaching of final year undergraduate nursing students
}

\author{
Joshua K. Muliira *, Dennis C. Fronda, Savithri Raman \\ Department of Adult Health and Critical, College of Nursing, Sultan Qaboos University, Muscat, Oman
}

Received: July 3, 2014

Accepted: November 9, 2014 Online Published: November 13, 2014

DOI: $10.5430 /$ jnep.v5n2p17

URL: http://dx.doi.org/10.5430/jnep.v5n2p17

\begin{abstract}
The aim of this study was to explore the perceptions of clinical preceptors (CPs) about difficult student situations during clinical teaching and the strategies they use to deal with such situations in the clinical setting. The participants were nurses who perform the role of clinical preceptor for senior nursing students at a University Hospital. The study used a descriptive qualitative approach to collect data through focus group discussions (FGD). Transcribed FGD data were content analyzed and coded to generate categories of difficult student situations in the clinical setting. The findings show that the CPs perceptions about difficult student situations in the clinical setting fall under four major categories of slothfulness, obstinateness, attentiveness and selfishness. The CPs also identified some of the strategies they use to manage these difficult student situations. In conclusion, it seems that during clinical teaching CPs experience challenging difficult student situations some of which can be considered as incivility and have significant implications for clinical teaching or learning and patient care outcomes. There is need for further studies about difficult student situations and incivility in the clinical setting and the effect it has on clinical student teaching, learning outcomes, and patient safety.
\end{abstract}

Key Words: Difficult student situations, Clinical teaching, Incivility, Preceptors, Nursing students, Nursing education

\section{Introduction}

Student incivility is increasing among nursing students and today it is one of the problems affecting nursing education in different countries. ${ }^{[1-4]}$ In the Middle East region there have been no studies about incivility of nursing students or the approaches nurse educators use to deal with this problem. In general, incivility has been defined as rude or disruptive behaviours which often results in psychological or physiological distress for the people involved, and if left unchecked, it may result into ominous situations. ${ }^{[5]}$ The other terms that have been used to characterize student incivility include difficult students, difficult student situations (DSS), inappropriate student behaviours, lateral violence, disruptive behaviours, abuse, conflicts, and others. ${ }^{[6]}$

Literature shows that as the population of nursing students becomes more diverse, nurse educators are increasingly facing the challenge of inappropriate behaviours or incivility and some of these behaviours are very difficult to understand because of cultural differences and lack of knowledge

\footnotetext{
*Correspondence: Joshua K. Muliira; Email: jkmuliira@gmail.com; Address: Department of Adult Health and Critical, College of Nursing, Sultan Qaboos University, P.O. Box 66 Al Khod, Muscat, Oman.
} 
about warning signs of potential incivility. ${ }^{[7]}$ Some of the behaviours that demonstrate typical incivility as reported by faculty in countries where this phenomenon has been studied include making disapproving groans, making sarcastic remarks or gestures, not paying attention in class, dominating class discussions, using cell phones during class, and cheating on examinations. ${ }^{[2]}$

A study conducted among nursing faculty in 41 states of United States of America reported that the most common uncivil behaviours of students include arriving late for class, holding distracting conversations, being unprepared for class, leaving class early and not turning up for class. ${ }^{[3]}$ Reports from China show the common uncivil student behaviours reported by nursing faculty to be; cheating on exams and quizzes; dominating class; using cell phones and pagers during class; holding distracting conversations; demanding make up exams; arriving late for class; and not paying attention. ${ }^{[4]}$ It should be noted that incivility or DSS are not limited to nursing education, because students in other health sciences such as medicine have also been noted to display uncivil behaviours and have been sometimes characterized as "difficult students". ${ }^{[8]}$

The students themselves also know that incivility exists and sometimes they feel that the faculty contribute to the escalation of incivility. ${ }^{[9]}$ Some of the themes students use when characterizing incivility includes difficult peer behaviour, poor communication techniques, unprofessional behaviour, stressful clinical environment and authority failure. ${ }^{[9]}$ But it should be emphasized that most of the existing studies that have reported about incivility or DSS in nursing education are based on observations made in the classroom environment. There are very few studies that have examined nursing students' incivility in the clinical setting despite the recognition that in such settings, incivility can be even more troublesome and has significant implications for patient safety, learning outcomes and well-being of the clinical faculty. ${ }^{[10]}$

In our experience as nurse educators, we have been receiving feedback from clinical preceptors $(\mathrm{CPs})$ showing that some senior nursing students are difficult to teach because of their behaviours. The CPs have highlighted that some behaviours of students lead to situations which are difficult to manage in the clinical setting. Based on the feedback from CPs we conducted an explorative study to understand what is perceived to be DSS. CPs are experienced staff nurses who teach, instruct, supervise and serve as role models for nursing students in training or new graduate nurses for a set period of time in a formalized program in the hospital setting. ${ }^{[11]}$ The CPs facilitate individualised clinical teaching and learning, and help to create a learning environment where theoretical knowledge is linked to clinical nursing practical skills and competencies. ${ }^{[12]}$ The purpose of this exploratory study was to describe the perceptions of CPs about DSS during clinical teaching and the strategies they use to deal with them in order to understand the extent of incivility in the clinical setting.

\section{Methods}

A descriptive qualitative approach and a two-group modified focus group discussion method was used to explore perspectives of CPs about DSS during clinical teaching of final year bachelor of science in nursing (BSN) students. This approach allowed the preceptors to discuss their experiences easily in their own words. ${ }^{[13]}$ The two-group modified focus group discussion method was preferred because it is inexpensive, flexible, facilitates information recall and all these attributes are helpful in generating rich data from participants. ${ }^{[14]}$ Most importantly the two-group modified focus group discussion method (also known as self disclosure) is very suitable for generating data about sensitive topics. ${ }^{[14,15]}$ Up to now there are no specific guidelines on the optimal number of focus groups that are considered enough for any qualitative study; therefore even a single focus group may be sufficient depending on the circumstances. The most essential requirement for data collection using the focus group discussion method is to maintain homogeneity and account for data saturation and redundancy. ${ }^{[13]}$

\subsection{Sample}

The participants for this study were CPs who are individuals involved in clinical teaching and supervision of final year BSN students during their last clinical course in the program. The CPs are experienced staff nurses who are assigned simultaneous roles of staff nurse and clinical preceptor. The CPs simultaneously provides one-on-one clinical teaching and supervision for senior nursing students, and patient care. All the CPs attained their professional education in English, and use the same language when providing services in the hospital. The CPs regularly participate in an annual workshop organized by the College of Nursing to orient them about the BSN program and clinical teaching requirements. This explorative study was conducted during the annual CP's orientation workshop. Before the workshop, the CPs were informed of an opportunity to participate in exploratory focus group discussions (FGD) about issues related to clinical teaching of BSN students and the need for voluntary consent before participating in the FGDs.

A total of $21 \mathrm{CPs}$ who attended the workshop gave consent to participate in the FGDs addressing different topics related clinical teaching. All the $21 \mathrm{CPs}$ were from the same Hospital but working in eleven (11) different clinical units/specialties (haematology-oncology, paediatrics, postnatal care, general surgery, general medicine, gynaecology, and intensive care unit). The other characteristic of the CPs are described in Table 1. The CPs who consented to participate in the study were 21 and 5 were selected to be part of the initial focus group discussion on the topic of DSS during clinical teaching. 
Table 1: Characteristics of clinical preceptors who participated in the annual orientation workshop

\begin{tabular}{|c|c|c|}
\hline Characteristic & Category & $\begin{array}{l}\text { Frequency (\%) } \\
(\mathrm{N}=21)\end{array}$ \\
\hline \multirow{2}{*}{ Gender } & Male & $3(14.3 \%)$ \\
\hline & Female & $18(85.7 \%)$ \\
\hline \multirow{3}{*}{$\begin{array}{l}\text { Highest level of professional (nursing) } \\
\text { education attained }\end{array}$} & Masters & $0(0 \%)$ \\
\hline & Bachelor & $11(52.4 \%)$ \\
\hline & Associate degree & $10(47.6 \%)$ \\
\hline \multirow{4}{*}{$\begin{array}{l}\text { Total years of clinical experience } \\
(\text { Mean }=14.43 \pm 5.4)\end{array}$} & $3-5$ & $4(19.1 \%)$ \\
\hline & $6-9$ & $1(4.8 \%)$ \\
\hline & $10-12$ & $1(4.8 \%)$ \\
\hline & $\geq 13$ & $15(71.4 \%)$ \\
\hline \multirow{3}{*}{$\begin{array}{l}\text { Years spent at the current hospital of } \\
\text { employment (Mean }=6.4 \pm 4.3 \text { ) }\end{array}$} & $3-6$ & $15(71.4 \%)$ \\
\hline & $7-10$ & $3(14.3 \%)$ \\
\hline & $\geq 11$ & $3(14.3 \%)$ \\
\hline \multirow{4}{*}{$\begin{array}{l}\text { Years since taking up preceptor role } \\
(\text { Mean }=3.6 \pm 3.5)\end{array}$} & $1-2$ & $11(52.4 \%)$ \\
\hline & $3-4$ & $6(28.6 \%)$ \\
\hline & $5-6$ & $1(4.8 \%)$ \\
\hline & $\geq 7$ & $3(14.3 \%)$ \\
\hline \multirow{3}{*}{$\begin{array}{l}\text { Approximate number students precepted at } \\
\text { the current hospital of employment since } \\
\text { taking up preceptor role (Mean }=4.1 \pm 3.0 \text { ) }\end{array}$} & $1-2$ & $7(33.3 \%)$ \\
\hline & $3-4$ & $9(42.9 \%)$ \\
\hline & $\geq 5$ & $5(23.8 \%)$ \\
\hline
\end{tabular}

\subsection{Data collection}

Prior to data collection, ethical approval was obtained by the authors' from the academic institution (the Research and Ethics Committee at the College of Nursing - CRC \#2012/11.07.2012). All participants signed a written consent form before participating in the focus group discussion and confidentiality was maintained by using pseudo labels for the CPs involved in the focus group discussion (FGD). The data collection occurred in two phases. Initially after receiving signed consent forms from the $\mathrm{CPs}$, the five $\mathrm{CPs}$ who agreed to discuss the topic of DSS were taken to a separate room where the FGD took place. The number of participants in the initial FGD was limited to five in order to accommodate for the sensitive nature of the topic and to facilitate in depth and orderly discussion of the topic. In order to start the FGD, the CPs were asked 1) What difficult student situations have you experienced in the clinical setting when precepting final year BSN students? and 2) What strategies have you used to deal with these situations in the clinical setting? The CPs spend two hours discussing the two questions. The FGD was moderated by a College of Nursing faculty member who was involved in teaching final years BSN students in their last clinical course. The moderator had an assistant who helped to record (audio recorded) the views and perspectives expressed during the FGD. Hand written notes summarizing emotions, reactions and main points (perspectives) from the FGD were also recorded by the assistant. The summary of mains points was shared with all the CPs in the FGD and they all agreed with the recorded points.
During the second phase, the summary of findings agreed upon in the initial FGD was shared with and examined by the second group of preceptors $(n=21)$. This large group of preceptors also included the five CPs from the first FDG. The contributions and reactions of the second large group were used to make modifications and additions to the findings and this helped to ensure agreement from the whole group. The second phase also provided validation of the initial FGD data and provided a second opportunity for the CPs to express additional ideas about the topic. During this second phase, the original questions were re-phrased and asked to the large group again as follows: What are the most common difficult student situations you have experienced in the clinical setting when precepting final year BSN students? and 2) What strategies do you commonly use to deal with these situations in the clinical setting? The questions were discussed for a period of approximately 30 minutes. In both groups, prompts were used to facilitate information flow and ensure consistency of the data.

\subsection{Data analysis}

The recorded data was transcribed verbatim and the resulting transcripts were given to 3 participants of the FGD to check for accuracy before thematic analysis was started. The resulting text was then analyzed thematically following the fifteen phases explained by Dey in 1993. ${ }^{[16]}$ In order to develop the coding categories, one of the investigators independently read through the FGD transcripts, taking notes on the major topics discussed. The first investigator to read the transcripts developed categories using one copy of the transcripts and then met with the team to clarify and revise 
them in order to determine final coding categories. From this record, a codebook was developed to ensure consistent application of the final coding categories. The codebook included the criteria for applying each category and a brief excerpt of data exemplifying each category. After the codebook was developed, the other two investigators independently read and manually analyzed the transcript using the code book to identify categories. The codes of each investigator were later reviewed by all the three investigators during team meetings to ensure agreement on the meaning in case of differences. The agreed upon codes were synthesized and grouped into exhaustive categories.

\section{Findings}

\subsection{Difficult student situations during clinical teaching}

The analysis of findings about DSS during clinical teaching in the clinical setting revealed four major categories of situations (slothfulness, obstinateness, lack of attentiveness, and selfishness) and these are presented below with supporting excerpts from each FGD.

\subsubsection{Slothfulness}

The CPs expressed that student slothfulness was common in the clinical setting. The perspectives of the CPs revealed that students who are sluggish and idle create situations that are difficult. The CPs stated that because they have other patient care responsibilities, they expect the final year BSN students to be independent, inquisitive and actively involved in patient care activities during clinical learning. The CPs reported examples of slothfulness such as reporting late on the clinical unit, taking long breaks in the middle of the shift, and leaving before giving endorsement to the next shift. The CPs noted that these tendencies are a sign of laziness, carelessness, lack of commitment and are difficult to manage in the clinical setting. Some of the views expressed by the CPs that show slothfulness are indicated below.

FGD1: "Ok, late coming to work... and uhmm, no commitment ... how about going for long breaks and not coming back. Coming late for work, most of the time, going for long breaks, not coming back. Not coming back sometimes."

FGD2: "Because they all gather in a group. ...... too lazy especially when they go together for a break as group". "Without informing us also..."

FGD3: "They many times show up late for clinical area. And these are the ones who are always not prepared, no readiness or enthusiasm to start the clinical assignments with preset objectives."

FGD4: "My favourite is this boy,-- he was always looking forward to go on long hours of leisure break, often comes late when called to real nursing interventions. Then there are those who always pretend to be busy, doing nothing and no help at all."

\subsubsection{Obstinateness}

The CPs felt that students who create DSS in the clinical setting are those who are adamant or reluctant to follow course guidelines, preceptor supervision arrangements, perform procedures without the presence of the preceptors and do not cooperate in doing patient care. The CPs noted that they commonly encounter behaviours categorized as obstinateness, especially because some final year BSN students feel that they know enough because they are about to graduate from the program or familiar with the clinical ward or unit. Some of the excerpts from the FDG that represent obstinateness are indicated below.

FGD1: "We are given specific course guidelines and I reorient them about the rules and guidelines to follow while in clinical. But however much you counsel them, they do a procedure without the presence of preceptor... They are not cooperative in doing bed side patient care... especially patient hygiene care, they don't like it."

FGD2: "They always have another explanation for not following the course guidelines and preceptors' advice.........they are good at answering back. Sometimes I feel unable to tell them something because they are not flexible. How can a student, say I don't like that correction..........doesn't like to be corrected."

FGD3: "Procedures, example, one example, let's say uhmm, that it's a procedure of wound dressing to be done, so they say no I don't want to do dressing today, let me do glucose monitoring........ They don't like all work that is dirty like when you say going for turning patient, they like only simple works."

FGD4: "Last term, this man was not following the roster. He was also selecting own preceptor and getting the signatures not from me. When exam time came he was very demanding, I want this procedure.......demanding ...it is not a request anymore, it's like an order already. If you advise them against something, they go away and the next day they select their own preceptor and they will get signature and they will go, next day you ask whose signature is it..."

\subsubsection{Attentiveness}

Preceptors reported that students who are not attentive are very difficult to teach in the clinical setting. Examples of such students are those who spend more time on their mobile phones, computer and internet rather than on direct patient care. The CPs commented that in some cases student's attentiveness is very limited and is affected by preference and interest in internet and gadgets such as smart phones. Some preceptors tried to use students' interest in technology to promote learning by asking them to access course materials and other learning materials posted on the online course 
webpage and hospital website. But despite these attempts, CPs still found it difficult to get the students to focus their attention on patient care, while at the same time juggling patient care and other clinical responsibilities. For instance the CPs noted that:

FGD1: "It is difficult to ask them to let go of the cell phone. They spend more time on the internet in the ward or on their mobile phone because sometimes.... Their cell phone is like their lifeline....."

FGD3: "The girls come do patient care for a little time. They only want to finish their school requirements like medication administration and then they will be into the internet, especially in the evening and night shifts. ...... It's not only on day shifts. Night duty they spend maximum time on the internet in the ward or on their mobile phone. Sometimes they forget about the patient."

FGD4: "When we are taking the patient for procedure they are not there, and you start hunting them, especially in the evening and night, it is not only the day time, but night duty and evening time will be worse."

\subsubsection{Selfishness}

CPs reported that they had difficulties handling preceptees who were so much self-centred. Some of the students were reported to be very demanding regardless of the patient needs, patient care and other clinical activities. The CPs reported that students did not like to be turned down and want to have their way in everything. Some of the statements exemplifying selfishness that came from the FGD are shown below.

FGD1: "They are more self centered and not into real patient care, more into what they want now. Preceptors are like somebody whom they have no relationship with. If you are strict on them, they will not come with the same preceptor, on the same shift they abandon and go to another staff and they seek audience with them only."

FGD2: "They will tell you, I want to practice procedures. Basic patient care I know already. They ask you to give medications and after the procedures, get signature to show instructor (faculty from College) that they did enough. Exam is the goal and prepare only for their performance......"

FGD3: "When they finish doing a little work they want to go attend to their needs, break, despite the work you have with other patients. They ask you to stop whatever you do to help them with what they want. Even not related to patient care or clinical........... and don't want to wait. They tell you my procedures, I have to go now and you are supposed to teach me first. And if it's time to go they don't care whether you are doing or patient needs ......... anything they just leave."

FGD4: "My favourite is when they tell do not take day off because I have to be with you to get enough shifts. One told me you cannot change your shift schedule because I have to finish my hour requirements."

\subsubsection{Strategies used to deal with difficult student situa- tions}

The analysis of findings revealed six main strategies the CPs were using to deal with DSS. The six strategies include: giving feedback and counselling, enforcing rules and regulations, giving simple tasks, acknowledging good behaviour and improvements, rewarding or penalizing during evaluation, reporting to supervisors, and doing nothing.

\subsubsection{Giving feedback and counselling}

FGD1: “Ok, First time late, excusable, that's only human, second time late, also, if there is a warning sometimes we really need to excuse, third time late, there is seriously something wrong so they probably need counselling."

FGD2: "First we will talk to them and once we get their feedback we inform the head nurse because they will be the one in direct contact with the instructors from the college."

FGD3: "So we inform......, no, no, we talk to student first, we need to talk, because preceptor is like a mother figure or father figure. So talk to preceptee......"

FGD4: "We talk to the preceptee and find out the problem. Find out the problem faced, and then, we only talk as a friendly supervisor, our next step, we have to inform the head nurse so they can take necessary action where this counselling fails and all the business will come under the college of nursing, you know. It's not our side, is it?"

\subsubsection{Enforce rules and regulations}

FGD1: "Ok, that's good, penalize them according to the rules and course regulations. I tell them how long break time is going to be and to report to me once back."

FGD2: "In ours it's not like that, two late means third time when you come late, you are the same as absent. When he leaves before endorsement time, ahh, ok, the attendance book they bring along, we don't sign it."

FGD3: "So now we will tell him please kindly don't use the mobile phone while you are on duty."

FGD4: “........does not sign their logbook, ok, especially when doing procedures without the preceptors, I also don't touch it. Only when I am present during the procedure, otherwise it's considered not done."

\subsubsection{Give them simple tasks}

FGD1: "Sometimes the issue is lack of cooperation during patient care. But when they are not changing, especially male students, I need to stand beside him; in whatever he does even simple tasks.” 
FGD2: "In such cases let the student work, build her from simple procedures, like positioning, bed making, bed bath, temperature taking, vital signs, all those simple things..."

FGD3: "I would suggest do not let him do anything, invasive stuff like injections, NG tube feeding.... Mistakes at that level can get us in trouble..."

\subsubsection{Acknowledge good behaviours and improvements}

FGD1: "I try to praise them in public if behaviour improves and when they do well, because sometimes you know, in front of everybody, I say they have done a little improvement".

FGD2: "I would say, hmmm... alhamdu, mashalla (Thank God), you are really good, and they feel good, you know this helps them to keep it up."

FGD3: “... but after the third time, he reformed, changed, so we should give him the chance, especially when he says and states that he was wrong, but without all the possible excuses."

\subsubsection{Reward or penalize during evaluation}

FGD1: "I tell him, look here brother, this will be reflected in your evaluation and don't get angry with me if I give you bad marks on this one."

FGD2: "I inform student, it will affect his evaluation...ok, kalas (end of story). Even going for a long breaks and not coming back on time will affect his evaluation and what not, it will scare them........"

FGD3: So, one of my charge nurses said no, just inform them of their objectives and patient assignment, and evaluate based on performance. Sometimes nothing actually helps; you can only force the horse to go near the water, isn't it? We can't make it to drink water."

FGD4: "No, but you have to give them warning and if no improvement you have to record and consider this during evaluation. Most of them change well and that way they pass well in clinical."

\subsubsection{Do nothing}

FGD2: "Sometimes it is the preceptor themselves because seriously my experience in this hospital, I don't want to name names, they don't do anything about it. Imagine how embarrassing, to be strict when others didn't do this."

FGD2: "Let the student work because sometimes not everybody got training in preceptor skills you know. I think that is also a good idea, because next day he will gona turn around and say, that what my preceptor did to me..."

FGD3: "Ok, because you know one day we had one preceptee who came in the evening late, he came and he was telling me blindly standing there, so this kid was standing there, so I said, ok........ I don't have time for this one."

FGD4: "It's a policy, and then it becomes an issue you see. So again a very big issue for us when they do that actually, you know our work is affected in the ward sometimes but again like you said, sometimes we are just doing them a favour, ok, allow them to select a staff they want to work with, and other things they want to do."

\subsubsection{Report to supervisor}

FGD1: "Sometimes I feel the boss is more powerful and respected to tackle them. Whatever advices given in private about bad behaviour, I tell the head nurse. Praise we can do it in public, but whatever advice give in private, I inform my head."

FGD2: "If they are already there, what we will do? We cannot send them back. Yah, I figured I just said ok, ok you go on today and we will resolve the issue tomorrow since you are already here on the floor, so we put him there, the next day we report it to the head nurse. After I don't know what action was taken?"

FGD3: "They don't like corrections anyway. I inform the charge nurse and she can deal with it. It's not that we don't know how to deal with them, but the bigger issues... so you know overall issues like not following rules and policies, ok.”

\section{Discussion}

The role of CPs is acknowledged as a critical part of clinical training and clinical competence attainment in nursing education. ${ }^{[17]}$ Therefore effective CPs are those who can perform well the roles of staff nurse and preceptor simultaneously. However doing both roles simultaneously can be stressful and burdensome especially if it involves dealing with DSS. Attempts to understand the DSS and the strategies CPs use to deal with them have significant implications for nursing education and clinical practice. The current study reveals some of the DSS and that being a CP is not entirely an upbeat experience.

The CPs who participated in this study faced DSS which they were sometimes not able to handle appropriately, while at other times they were well handled using appropriate strategies. The DSS reported by the CPs belonged mainly to four categories of slothfulness, obstinateness, attentiveness, and selfishness. Some of these DSS can be attributed to the generation to which the current nursing students belong to, the level of support provided to CPs by the nursing schools or the experience and preparation of the CPs before they take up clinical teaching roles. Other studies have reported DSS which are closely similar to those highlighted by our study. A study conducted in Australia reported that some of the challenges that CPs of nursing and midwifery students 
face are related to personality clashes with students, and finding time to support unmotivated students. ${ }^{[18]}$ Literature also shows that when CPs are supporting nursing students in the clinical environment they many times experience role confusion, have difficulty with students who do not know what to do and require greater involvement by universities in their preparations especially, if they are responsible for direct student assessment. ${ }^{[19]}$

In order to manage the different categories of the DSS (slothfulness, obstinateness, attentiveness, and selfishness), the CPs need the support of the faculty. Earlier studies show that when CPs are faced with DSS, positive outcomes for all parties involved emerges if academic faculty provide adequate support and share in the responsibility of student supervision. ${ }^{[20]}$ The CPs need considerable support and advice from academic faculty in order to make critical decisions about DSS. The findings of this explorative study show that there is a need for nursing education institutions and clinical agencies to have continuous proactive and deliberate programs for preparing and supporting CPs. Usher and colleagues recommends investing more in orientation of preceptors and to emphasize aspects such as student evaluation, giving feedback, teaching skills, and rewards for preceptors. ${ }^{[11]}$ When preceptors are provided with adequate orientation and support they are more likely to be effective. ${ }^{[11,20]}$

It is well documented that DSS or incivility undermines the culture of safety, and the intimidation created by such behaviours leads to an environment of hostility and disrespect, all of which affect morale, increase staff turnover, distraction, errors and subsequently diminish patient safety. ${ }^{[21]}$ The effects of student incivility which have been reported to occur in nursing faculty (decreased self esteem, loss of confidence in teaching ability, loss of sleep, loss of time, retreat or withdrawal from teaching jobs ${ }^{[1]}$ and high stress levels, ${ }^{[22]}$ can also occur in CPs. The above potential outcomes of DSS or incivility entrenches the need for deliberate and proactive support for CPs from nursing education institutions and clinical agencies.

The support provided to CPs can be in the form of training and increasing student readiness for clinical learning or practice. Burns and colleagues argue that some DSS are caused by student performance, but sometimes the issue is one of student dissatisfaction and lack of a good match between the student learning styles and CPs style or the characteristics of the clinical unit. ${ }^{[23]}$ DSS can also arise if the CPs and the students are from two different generations and therefore different values, ideals, ethics, culture, perceptions about civility or professionalism, and this increases the likelihood of conflict. ${ }^{[20]}$ The differences between the CPs and nursing students are likely to be poorly navigated when the CPs transition into the teaching roles with little or no formal preparation on how to be an educator. ${ }^{[24]}$ The other forms of support that can be used to address DSS faced by CPs can be in the form of motivation such as remuneration for the

Published by Sciedu Press time and energy expended by CPs and strategies to address issues such as poor communication between the faculty and CPs, burden of being responsible for the success and failure of a student, perceived powerlessness during decision making about the student, and lack of skills to manage conflict situations with students. ${ }^{[25]}$

Training of CPs and preparation of students for clinical learning can help to familiarize, increase acceptance and consistent application of the good strategies the CPs reported to be using to manage DSS such as giving feedback and counselling, enforcing rules and regulations, giving simple tasks, acknowledging good behaviour and improvements, rewarding or penalizing during evaluation, and reporting to supervisors. The training programs can also be used to give CPs concrete approaches to precepting when faced with DDS. Such approaches could include adjusting the level of precepting, incorporating a variety of clinical teaching strategies and techniques to enhance student learning and professional development, developing a trustful relationship with students, using reflection and critical thinking activities and evaluating this process on an on-going basis. ${ }^{[26]}$

Literature shows that there are other strategies for dealing with incivility such as; developing policies that clearly define uncivil behaviours for both students and faculty; fostering supportive and respectful student and faculty relationships; offering educational opportunities about incivility to both students and faculty; ${ }^{[27,28]}$ and developing protocols for managing incivility and disruptive behaviours as it occurs. ${ }^{[4]}$ Studies focusing on other categories of students pursuing health care professions such medicine shows that one of the best strategy for dealing with incivility is remediating the difficult learner. ${ }^{[8]}$ The most successful remediation programs for students have been found to be those which have the four critical elements of: initial assessment using multiple assessment strategies to identify deficiencies; diagnosis of problems and development of an individualized learning plan; instruction which include deliberate practice, feedback and reflection; and reassessment and certification of competence. ${ }^{[29]}$ Preceptors can also be supported and facilitated through group supervision by a nurse lecturer from the nursing school. ${ }^{[30]}$ Using a nurse lecturer to supervise and support preceptors has been reported to enhance CPs positive experiences, pedagogical competences, personal competences and role awareness. ${ }^{[30]}$

\section{Limitations of the study}

It should be recognized that this was an explorative study and as such it used CPs who were all from the same hospital. Furthermore, the CPs were all staff nurses and the head nurses whom they report to were not available to participate in the FGD. Therefore the findings may not be representative of the whole spectrum of DSS or incivility and the strategies employed to address them. Despite its limitations, 
the current findings can be used as foundation for further studies about red flags that need to be monitored and can provide initial guidance about the interventions needed to prevent student incivility during clinical teaching and learning.

\section{Conclusion}

It seems that during clinical teaching CPs experience challenging DSS and some of these situations amount to some form of incivility. In the clinical setting, no matter the source or label used to characterize DSS or incivility, they are inappropriate and the consequences have wider implications for patient care outcomes and student learning outcomes. DSS or incivility undermines the culture of safety, clinical teaching and learning, and the process of mentoring and role modelling of senior student nurses into responsible professionals. There is need for additional studies about student incivility in the clinical setting in order to develop effective deliberate and proactive preventive strategies and support programs for those involved in clinical teaching such as the CPs.

\section{Acknowledgements}

The authors would like to thank the clinical preceptors for sharing their valuable experiences and the College of Nursing for funding the activities that led to the study.

\section{Conflicts of Interest Disclosure}

The authors declare no conflict of interest.

\section{References}

[1] Luparell S. The effects of student incivility on nursing faculty. Journal of Nursing Education. 2007a; 46(1): 15-19. PMID:17302095

[2] Clark CM. Springer PJ. Incivility in nursing education: A descriptive study of definitions and prevalence. Journal of Nursing Education. 2007; 46(1): 7-14. PMID:17302094

[3] Clark C. The dance of incivility in nursing education as described by nursing faculty and students. Advances in Nursing Science. 2008; 31(4): E37-E54. PMID:19033739 http://dx.doi .org/10.1097 /01. ANS.0000341419.96338.a3

[4] Clark CM. Otterness NS. Jun WY. Allerton BW. Juan CM. Black M. Wei F. Descriptive study of student incivility in the People's Republic of China. Journal of Cultural Diversity. 2010; 17(4): 136-143. PMID:22303648

[5] Clark CM. Farnsworth J. Landrum RE. Development and description of the incivility in nursing education (INE) survey. Journal of Theory Constructing \& Testing. 2009; 13(1): 7-15.

[6] McNamara SA. Incivility in nursing: Unsafe nurse, unsafe patients. AORN Journal. 2012; 95(4); 535-540. PMID:22464626 http:// $\mathrm{dx}$.doi.org/10.1016/j.aorn. 2012.01.020

[7] Davis SP. Davis DD. Williams DD. Challenges and issues facing the future of nursing education: Implications for ethnic minority faculty and students. Journal of Cultural Diversity. 2010; 17 (4): 122-126. PMID:22303646

[8] Ronan-Bentle SE. Avegno J. Hegarty CB. Manthey DE. Dealing with the difficult student in emergency medicine. International Journal of Emergency Medicine. 2011; 4 (39): 1-6.

[9] Altimiller G. Student perceptions of incivility in nursing education: Implications for educators. Nursing Education Perspective. 2012; 3 (1): 15-20. http://dx.doi.org/10.5480/1536-5026-33.1. 15

[10] Luparell S. Incivility in Nursing: The connection between academia and clinical setting. Critical Care Nurse. 2011; 31(2): 92-95. PMID:21459868 http://dx.doi.org/10.4037/ccn2011171

[11] Usher K. Nolan C. Reser P. Owens J. Tollefson J. An exploration of the preceptor role: Preceptors' perceptions of benefits, rewards, supports and commitment to the preceptor role. Journal of Advanced Nursing. 1999; 29(2): 506-514. PMID:10197953 http: //dx.doi.org/10.1046/j.1365-2648.1999.00914.x

[12] Murray CJ. Main A. Role modelling as a teaching method for student mentors. Nursing Times. 2005; 101(26): 30-33. PMID: 16010841
[13] McLafferty I. Focus interviews as a data collecting strategy. Journal of Advanced Nursing. 2004; 48(2): 187-194. PMID:15369499 http://dx.doi.org/10.1111/j.1365-2648.2004.03186.x

[14] Speziale HS, Streubert HJ, Carpenter DR. Qualitative research in nursing: Advancing the humanistic imperative. Lippincott Williams \& Wilkins, 2011.

[15] Freeman T. 'Best practice' in focus group research: Making sense of different views. Journal of Advanced Nursing. 2006; 56(5): 491497. PMID:17078825 http://dx.doi.org/10.1111/j.1365-2 $648.2006 .04043 . x$

[16] Dey I. Qualitative Data Analysis. London: Routledge; 1993. http: //dx.doi.org/10.4324/9780203412497

[17] McCarthy B. Murphy S. Preceptors' experiences of clinically educating and assessing undergraduate nursing students: An Irish context. Journal of Nursing Management. 2010; 18(2): 234244. PMID:20465751 http://dx.doi .org/10.1111/j.1365-2 $834.2010 .01050 \cdot \mathrm{x}$

[18] O’Brien A. Giles M. Dempsey S. Lynne S. McGregor ME. Kable A. Parmenter G. Parker V. Evaluating the preceptor role for preregistration nursing and midwifery student clinical education. Nurse Education Today. 2014; 34(1): 19-24. PMID:23623277 http://dx .doi.org/10.1016/j.nedt.2013.03.015

[19] Broadbent M. Moxham L. Sander T. Walker S. Dwyer T. Supporting bachelor of nursing students within the clinical environment: Perspectives of preceptors. Nurse Education in Practice. 2014; 14(4): 403-409. PMID:24439528 http://dx.doi.org/10.1016 /j.nepr.2013.12.003

[20] Luhanga F. Yonge O. Myrick F. Precepting an unsafe student: The role of the faculty. Nurse Education Today. 2008; 28(2): 227231. PMID:17553601 http://dx.doi.org/10.1016/j.nedt. 2007.04 .001

[21] Rosenstein AH. O'Daniel M. Impact and implications of disruptive behaviour in the perioperative arena. Journal of the American College of Surgeons. 2006; 203(1): 96-105. PMID:16798492 http: //dx.doi.org/10.1016/j.jamcollsurg. 2006.03.027

[22] Clark CM. Kenaley BLD. Faculty empowerment of students to foster civility in nursing education: A merging of two conceptual models. Nursing Outlook. 2011; 59 (3): 158-165. PMID:21497862 http://dx.doi.org/10.1016/j.outlook. 2010.12.005

[23] Burns C. Beauchesne M. Ryan-Krause P. Sawin K. Mastering the preceptor role: Challenges of clinical teaching. Journal of Pediatric Health Care. 2006; 20(3): 172-183. PMID:16675378 http: //dx.doi.org/10.1016/j.pedhc.2005.10.012 
[24] Luparell S. Managing difficult student situations: Lessons learned. In M. H. Oermann \& K. T. Heinrich (Eds). Annual review of nursing education. New York: Springer; 2007b. 101-110.

[25] Barker ER. Pittman O. Becoming a super preceptor: A practical guide to preceptorship in today's clinical climate. Journal of the American Academy of Nurse Practitioners. 2010; 22(3): 144 149. PMID:20236398 http://dx.doi.org/10.1111/j.1745-7 599.2009.00487.x

[26] Elisabeth C. Christine WH. Ewa P. Teaching during clinical practice: Strategies and techniques used by preceptors in nursing education. Nurse Education Today. 2009; 29(5): 522-526. PMID:19108935 http://dx.doi.org/10.1016/j.nedt.2008.11.012

[27] Clark CM. Faculty and student assessment of and experience with incivility in nursing education. Journal of Nursing Education. 2007; 47(10): 458-465. http://dx.doi.org/10.3928/01484834-2 0081001-03
[28] Gallo VJ. Incivility in nursing education: A review of the literature. Teaching \& Learning in Nursing. 2012; 7(2): 62-66. http: //dx.doi.org/10.1016/j.teln.2011.11.006

[29] Hauer KE. Ciccone A. Henzel TR. Katsufrakis P. Miller S H. Norcross WA. Papadakis MA. Irby DM. Remediation of the deficiencies of physicians across the continuum from medical school to practice: A thematic review of literature. Academic Medicine. 2009; 84(12): 1822-1832. PMID:19940595 http://dx.doi.org/10. 1097/ACM. Ob013e3181bf3170

[30] Andersson CS. Danielsson A. Hov R. Athlin E. Expectations and experiences of group supervision: Swedish and Norwegian preceptors' perspectives. Journal of Nursing Management. 2013; 21(2): 263272. PMID:23410222 http://dx.doi.org/10.1111/j.1365-2 $834.2012 .01398 . x$ 